\title{
Correction to: Virtual Environments to Stimulate Skills in the Early Childhood Education Stage
}

Jorge S. Sánchez, Jessica S. Ortiz, Paola M. Velasco,

Washington X. Quevedo, Cesar A. Naranjo, Paulina Ayala, Carlos D. Gordon, and Víctor H. Andaluz

\section{Correction to:}

Chapter "Virtual Environments to Stimulate Skills

in the Early Childhood Education Stage" in: L. T. De Paolis

and P. Bourdot (Eds.): Augmented Reality, Virtual Reality,

and Computer Graphics, LNCS 10850,

https://doi.org/10.1007/978-3-319-95270-3_24

In the originally published version the names of two authors were incorrectly spelled as "Paulina X. Ayala" and "Carlos X. Gordon". They were corrected to "Paulina Ayala" and "Carlos D. Gordon". In addition the e-mail address of Carlos D. Gordon was corrected from cx.gordon@uta.edu.ec to cd.gordon@uta.edu.ec.

The updated online version of this chapter can be found at https://doi.org/10.1007/978-3-319-95270-3_24 